\title{
Palladium Nanoparticles Supported on Magnetic Carbon- Coated Cobalt Nanobeads: Highly Active and Recyclable Catalysts for Alkene Hydrogenation
}

\author{
Quirin M. Kainz, Roland Linhardt, Robert N. Grass, Gianvito Vilé, Javier Pérez-Ramírez, \\ Wendelin J. Stark, and Oliver Reiser*
}

Palladium nanoparticles are deposited on the surface of highly magnetic carbon-coated cobalt nanoparticles. In contrast to the established synthesis of $\mathrm{Pd}$ nanoparticles via reduction of $\mathrm{Pd}$ (II) precursors, the microwave decomposition of a $\mathrm{Pd}(0)$ source leads to a more efficient $\mathrm{Pd}$ deposition, resulting in a material with considerably higher activity in the hydrogenation of alkenes. Systematic variation of the Pd loading on the carbon-coated cobalt nanoparticle surface reveals a distinct trend to higher activities with decreased loading of $\mathrm{Pd}$. The activity of the catalyst is further improved by the addition of 10 vol\% $\mathrm{Et}_{2} \mathrm{O}$ to iso-propanol that is found to be the solvent of choice. With respect to activity (turnover frequencies up to $11095 \mathrm{~h}^{-1}$ ), handling, recyclability through magnetic decantation, and leaching of $\mathrm{Pd}$ ( $\leq 6 \mathrm{ppm} / \mathrm{cycle})$, this novel magnetic hybrid material compares favorably to conventional $\mathrm{Pd} / \mathrm{C}$ or Pd@CNT catalysts.

\section{Introduction}

Catalytic hydrogenations are among the most important and widely accessed transformations in the chemical industry. If molecular hydrogen is used and the catalyst is recyclable, this method is atom economic and arguably the cleanest possible way to reduce an organic compound. ${ }^{[1]}$ The recovery and recycling of catalysts comes more and more into focus not only from an economical but also from an ecological perspective driven by the rise of green and sustainable chemistry. ${ }^{[2]}$

Generally, homogeneous catalysts feature high levels of activity and selectivity since they are uniform on a molecular level and readily dissolved in the reaction medium. However, especially on large scale it is often tedious and expensive to efficiently separate these catalysts from reaction mixtures, which is important due to the high costs of catalysts and to avoid heavy metal contamination of the final products, a key issue

Q. M. Kainz, R. Linhardt, Prof. O. Reiser Institute of Organic Chemistry University of Regensburg

Universitätsstr. 31, 93053, Regensburg, Germany

E-mail: oliver.reiser@chemie.uni-regensburg.de

Dr. R. N. Grass, G. Vilé, Prof. J. Pérez-Ramírez,

Prof. W. J. Stark

Institute for Chemical and Bioengineering

ETH Zurich, Wolfgang-Pauli-Str. 10, 8093, Zürich, Switzerland

DOI: $10.1002 / \mathrm{adfm} .201303277$ in pharmaceutical industry. ${ }^{[3]}$ In fact, in about $80 \%$ of the industrially relevant catalytic transformations heterogeneous catalyst systems are applied. ${ }^{[4]}$ Despite considerable research efforts, predominantly the sites on the surface of the porous supports are catalytically active, reducing the overall activity of such heterogeneous systems. ${ }^{[5]}$

Due to their high surface-to-volume ratio, nanocatalysts, e.g. transition-metal nanoparticles, nicely bridge the gap between both worlds by featuring attributes of homogeneous (high activity and selectivity) and heterogeneous (easy separation and recycling) systems. However, quite expensive ultracentrifugation has to be used to separate nano-sized particles instead of simple filtration. In addition, such particles tend to agglomerate to the bulk material without the addition of stabilizers, which hampers their activity by shielding the surface. ${ }^{[5,6]}$ Therefore, many attempts have been made to stabilize nanoparticles by immobilization on various functionalized and unfunctionalized supports, such as polymers, ${ }^{[7]}$ silica, ${ }^{[8]}$ zeolites, ${ }^{[9]}$ carbon, ${ }^{[10]}$ graphene, ${ }^{[11]}$ and carbon nanotubes (CNTs). ${ }^{[12-14]}$ However, most of these supports have serious drawbacks like a complicated synthesis, hampered diffusion kinetics, or tedious separation via centrifugation. An elegant way of merging high surface-area with convenient recovery via magnetic decantation is the application of magnetic nanoparticles as supports. Recent examples demonstrate the successful synthesis of palladium nanoparticles on the surface of magnetic substrates, e.g., polymer/silica/carbon-coated magnetite particles, ${ }^{[15,16]}$ magnetite-graphene composites, ${ }^{[17,18]}$ carbon-coated FeNi nanoparticles, ${ }^{[19]}$ and ordered mesoporous carbon doped with $\mathrm{Co} / \mathrm{C}$ nanoparticles. ${ }^{[20]}$

We report here a novel nanoparticle-on-nanoparticle hybrid system, which consists of three components: (i) a nano-sized cobalt core, which provides higher magnetization than conventional metal oxides allowing separation of the catalyst within seconds; (ii) several carbon shells, which protect the core and stabilize attached catalysts; (iii) palladium nanoparticles immobilized on the surface of the carbon shells showing exceptionally high catalytic activity in hydrogenation reactions. Key features of this study include the evaluation of different palladium sources and conditions for the synthesis of the Pd nanoparticles, 
investigation of the influence of various palladium loadings on the catalytic activity, and leaching and recycling tests.

\section{Results and Discussion}

Carbon-coated cobalt nanoparticles $(\mathrm{Co} / \mathrm{C})$ were used as magnetic supports. The large scale synthesis $\left(>30 \mathrm{~g} \mathrm{~h}^{-1}\right)$ of these magnetic beads via reducing flame spray pyrolysis was recently reported by Stark et al. ${ }^{[21]}$ Unique features are a remarkably high chemical and thermal stability due to the graphene-like shell and a saturation magnetization (158 emu g ${ }^{-1}$ ) equivalent to that of bulk cobalt, exceeding common iron oxide (e.g., magnetite) beads by a factor of five. ${ }^{[2]}$ Furthermore, the raw material costs (cobalt carboxylate and acetylene) for manufacturing $\mathrm{Co} / \mathrm{C}$ nanoparticles following this route can be estimated as $<100 \mathrm{USD} / \mathrm{kg}$. ${ }^{[23]}$ We successfully functionalized the carbon surface of the $\mathrm{Co} / \mathrm{C}$ beads by covalent and/or non-covalent methods $^{[24]}$ leading to various applications, e.g., to recyclable supports for catalysts, ${ }^{[25,26]}$ for the extraction of vitamins and contaminants from aqueous solutions, ${ }^{[27]}$ or for the purification of blood. ${ }^{[28]}$ The high magnetization of the beads allows continuous-flow applications using external magnetic fields rather than membranes to contain the catalyst. ${ }^{[29]}$ High loading magnetic reagents and scavengers are also accessible after the introduction of polymer shells to the Co/C nanoparticles. ${ }^{[30]}$

Since carbon materials are reported to provide significant stabilization to Pd nanoparticles, presumably through strong $\pi$-interactions with $\mathrm{sp}^{2}$ carbon atoms, ${ }^{[17,31]}$ the highly magnetic $\mathrm{Co} / \mathrm{C}$ nanoparticles seem to be an ideal support for the deposition of such nanoparticles. A procedure described by Urriolabeitia et al. ${ }^{[14]}$ was modified to synthesize Pd nanoparticles on the surface of Co/C nanobeads 1: $\mathrm{Pd}_{2}(\mathrm{dba})_{3} \cdot \mathrm{CHCl}_{3}$ as stable $\mathrm{Pd}(0)$ source and $\mathrm{Co} / \mathrm{C}$ nanoparticles, which are very susceptible to microwave irradiation, ${ }^{[32]}$ were heated in a focused microwave oven (Scheme 1) leading to the formation of Pd nanoparticles on the carbon surface of the Co/C support in only 2 min (Pd@Co/C 2a-f).

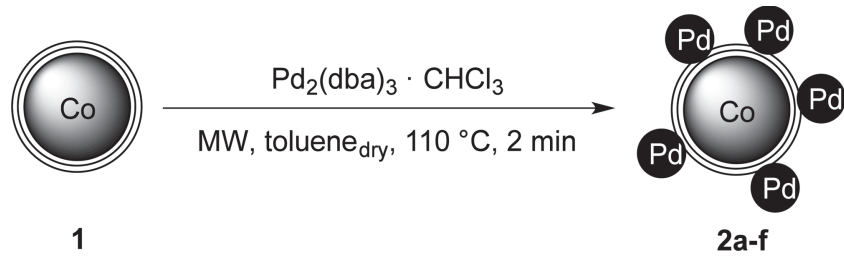

Scheme 1. Microwave-synthesis of Pd@Co/C nanocomposites.

In order to determine the effects of different loadings and dispersions of $\mathrm{Pd}$ nanoparticles on the surface of the $\mathrm{Co} / \mathrm{C}$ supports, 2a-f was synthesized with $\mathrm{Pd}$ contents ranging from $14.3 \mathrm{wt} \%$ to $0.2 \mathrm{wt} \%$ (Table 1 , entry $1-6)$. In all cases, the incorporation of $\mathrm{Pd}$ was nearly quantitative $(92-100 \%$, Figure 1a) as determined by inductively coupled plasma optical emission spectrometry (ICP-OES). $\mathrm{Pd}_{2}(\mathrm{dba})_{3}$ lacking the chloroform adduct was additionally tested as $\operatorname{Pd}(0)$ source under identical conditions in the microwave synthesis (Table 1 , entry $7+8$ ).

However, at two different concentrations ( 0.4 and $0.1 \mathrm{wt} \%)$, a palladium incorporation of only 62 and $71 \%$ was measured (Figure 1a). These results indicate a beneficial influence of the chloroform adduct in the formation of $\mathrm{Pd}(0)$ clusters and nanoparticles. Furthermore, $\mathrm{Na}_{2} \mathrm{PdCl}_{4}$, a $\mathrm{Pd}(\mathrm{II})$ source commonly used for the synthesis of Pd nanoparticles, was also evaluated. A dispersion of 1 in an aqueous solution of $\mathrm{Na}_{2} \mathrm{PdCl}_{4}$ was treated with either $\mathrm{NaBH}_{4}(\mathbf{2} \mathbf{i})$ or stirred under $\mathrm{H}_{2}$ atmosphere $(2 \mathbf{j})$ to reduce the $\operatorname{Pd}(\mathrm{II})$ salt to $\operatorname{Pd}(0)$ nanoparticles (Table 1, entry 9,10 ). Analysis of the resulting nanocomposites resulted in $87 \%$ Pd deposition in the case of $\mathrm{NaBH}_{4}$ reduction and $81 \%$ in the case of $\mathrm{H}_{2}$ reduction. Due to their unipolar nature, the particles 1 are less dispersible in an aqueous solution rather than in toluene as used in the microwave synthesis starting from $\operatorname{Pd}(0)$, which might account for the inferior results obtained by the reductive method starting from $\mathrm{Pd}(\mathrm{II})$.

The so synthesized Pd@Co/C hybrid materials were subsequently characterized by a series of techniques. The Pd dispersion and the average size of the $\mathrm{Pd}$ nanoparticles were

Table 1. Synthesis of Pd@Co/C nanoparticles with varying Pd loadings.

\begin{tabular}{|c|c|c|c|c|c|c|c|c|c|}
\hline entry & index & Pd source & method of synthesis ${ }^{a)}$ & $\begin{array}{c}\text { Pd incorporated } \\
{[\%]^{b)}}\end{array}$ & $\begin{array}{l}\text { Pd loading } \\
{\left[\mathrm{mmol} \mathrm{g}^{-1}\right]^{\mathrm{b})}}\end{array}$ & $\begin{array}{c}\text { Pd content }{ }^{b)} \\
\text { [wt\%] }\end{array}$ & $\begin{array}{c}\text { Pd dispersion } \\
{[\%]^{c)}}\end{array}$ & $\begin{array}{c}d_{\mathrm{Pd}} \\
{[\mathrm{nm}]^{\mathrm{c})}}\end{array}$ & $\begin{array}{c}S_{P d} \\
{\left[\mathrm{~m}^{2} \mathrm{~g}^{-1}\right]^{\mathrm{c})}}\end{array}$ \\
\hline 1 & $2 a$ & $\mathrm{Pd}_{2}(\mathrm{dba})_{3} \cdot \mathrm{CHCl}_{3}$ & A & 92 & 1.34 & 14.3 & & & \\
\hline 2 & $2 b$ & $\mathrm{Pd}_{2}(\mathrm{dba})_{3} \cdot \mathrm{CHCl}_{3}$ & A & 100 & 0.83 & 8.8 & 4 & 30.4 & 8 \\
\hline 3 & $2 c$ & $\mathrm{Pd}_{2}(\mathrm{dba})_{3} \cdot \mathrm{CHCl}_{3}$ & A & 98 & 0.41 & 4.4 & & $5-10^{d)}$ & \\
\hline 4 & $2 d$ & $\mathrm{Pd}_{2}(\mathrm{dba})_{3} \cdot \mathrm{CHCl}_{3}$ & A & 100 & 0.15 & 1.6 & 22 & 6.3 & 54 \\
\hline 5 & $2 e$ & $\mathrm{Pd}_{2}(\mathrm{dba})_{3} \cdot \mathrm{CHCl}_{3}$ & A & 96 & 0.073 & 0.8 & 35 & 3.8 & 95 \\
\hline 6 & $2 f$ & $\mathrm{Pd}_{2}(\mathrm{dba})_{3} \cdot \mathrm{CHCl}_{3}$ & A & 100 & 0.015 & 0.2 & 47 & 2.7 & 113 \\
\hline 7 & $2 g$ & $\mathrm{Pd}_{2}(\mathrm{dba})_{3}$ & A & 62 & 0.042 & 0.4 & & & \\
\hline 8 & $2 \mathrm{~h}$ & $\mathrm{Pd}_{2}(\mathrm{dba})_{3}$ & A & 71 & 0.012 & 0.1 & & & \\
\hline 9 & $2 \mathbf{i}$ & $\mathrm{Na}_{2} \mathrm{PdCl}_{4}$ & B & 87 & 0.013 & 0.1 & & & \\
\hline 10 & $2 j$ & $\mathrm{Na}_{2} \mathrm{PdCl}_{4}$ & C & 81 & 0.012 & 0.1 & & & \\
\hline
\end{tabular}

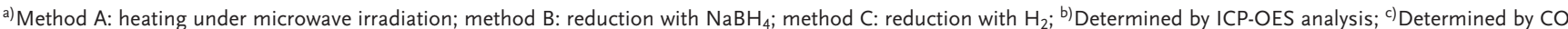
pulse chemisorption; ${ }^{d)}$ Determined by transmission electron microscopy (TEM). 
a)

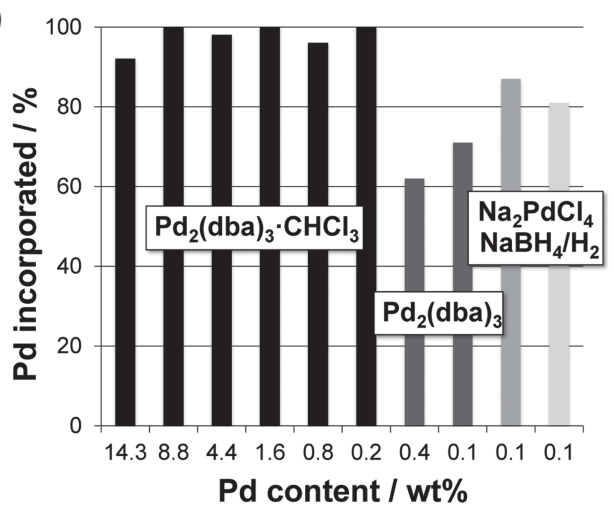

b)

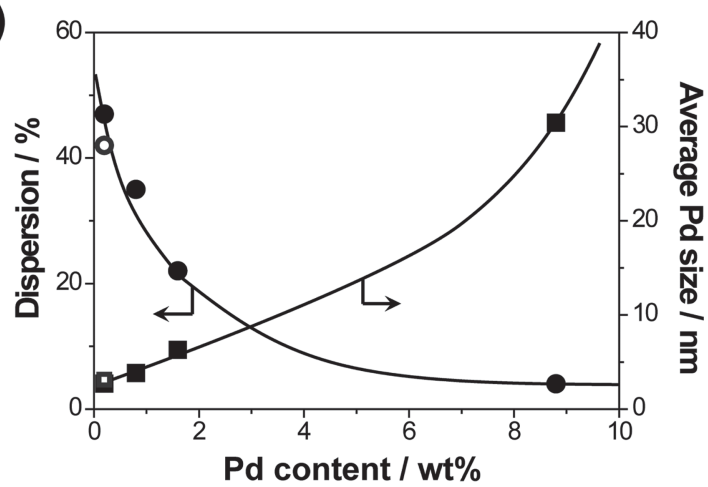

c)

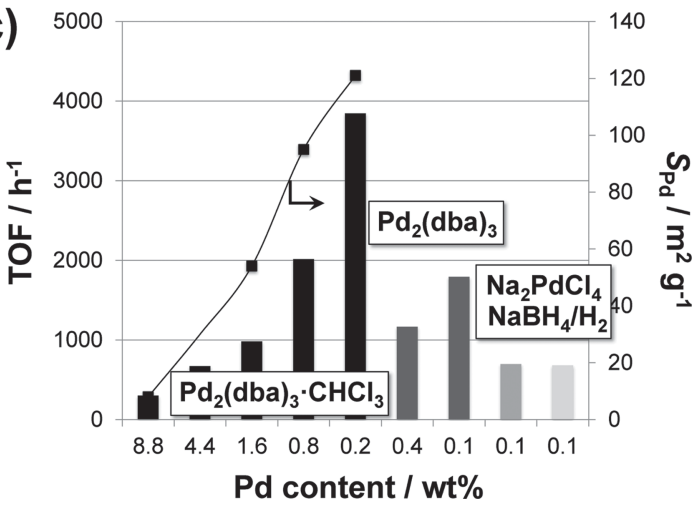

Figure 1. a) Synthesis of Pd nanoparticles on the surface of $\mathrm{Co} / \mathrm{C}$ nanobeads varying the Pd source and the Pd concentration. b) Dispersion and size of $\mathrm{Pd}$ nanoparticles $(\mathbf{2} \mathbf{b}, \mathbf{d}, \mathbf{e}, \mathbf{f})$ determined by $\mathrm{CO}$ pulse chemisorption measurements. The open symbols indicate a sample after six runs of catalysis. c) Hydrogenation tests of trans-stilbene at a Pd catalyst loading of $0.1 \mathrm{~mol} \%$. (TOF = turnover frequency). The best results were obtained for Pd@Co/C particles with a low Pd content of 0.2 wt\% (2f) synthesized by $\mathrm{MW}$ decomposition of $\mathrm{Pd}_{2}(\mathrm{dba})_{3} \cdot \mathrm{CHCl}_{3}$.

determined by $\mathrm{CO}$ pulse chemisorption (Figure 1b). A reference sample of 1 did not show any adsorption of CO, strongly suggesting that all Co particles were well coated by carbon. The smallest nanoparticles $(2.7 \mathrm{~nm})$ and highest Pd dispersion (47\%) were determined for the nanocomposite $\mathbf{2} \mathbf{f}$ with the lowest $\mathrm{Pd}$ loading (Table 1, entry 6). Further studies nicely showed a trend to larger Pd nanoparticles as well as a decreased dispersion by increasing the Pd content in the nanocomposite (Figure 1b). At $8.8 \mathrm{wt} \% \mathrm{Pd}$ nanoparticles with a large mean size of ca. $30 \mathrm{~nm}$ and a very low dispersion of $4 \%$ were observed (Table 1, Entry 2). Consequently, the exposed surface of the Pd nanoparticles, a key factor for catalytic activity, decreases with higher Pd loadings. Transmission electron microscopy (TEM) of nanoparticles 2c with 4.4 wt\% Pd indeed showed deposition of Pd nanoparticles with a size of about $5-10 \mathrm{~nm}$ on the surface of the larger Co/C supports, which have an average diameter of $25 \mathrm{~nm}$ (Figure 2). ${ }^{[21]}$

An unambiguous assignment of the particle size distribution, however, was not possible due to the rather broad size distribution of the $\mathrm{Co} / \mathrm{C}$ supports. Especially for nanocomposites with low Pd loadings, a clear determination of the very small $\mathrm{Pd}$ nanoparticles was difficult. Energy-dispersive X-ray spectroscopy (EDX) confirmed, that the nanocomposites comprise of the elements Co, C, and Pd, which are derived from cobalt core, carbon shell, and Pd deposited on the surface.

Additionally, X-ray powder diffraction (XRD) was performed. With Pd loadings ranging from 0.2 to $8.8 \mathrm{wt} \%$ only the characteristic diffraction lines at $2 \theta$ of $44.2^{\circ}, 51.5^{\circ}$, and $75.8^{\circ}$ corresponding to the diffraction of (111), (200), and (220) of the cobalt core were observed. Only for 2a, featuring a high loading of $14.3 \mathrm{wt} \% \mathrm{Pd}$ one broad reflection at $2 \theta$ of $39.9^{\circ}$ was detected in addition to the cobalt reflections, which can be indexed as the diffraction (111) of crystalline $\mathrm{Pd}(0)$ indicating that $\mathrm{Pd}$ exists in the reduced form $\mathrm{Pd}(0)$ instead of $\mathrm{Pd}(\mathrm{II})$.

The nanocomposites were subsequently tested as catalysts for the hydrogenation of alkenes using molecular hydrogen. As a first test substrate trans-stilbene was hydrogenated using particles $\mathbf{2 b}$-j having different Pd contents (Table 2 , entry $1-5$ ). The total amount of particles was adjusted to obtain the same low Pd content of $0.1 \mathrm{~mol} \%$ for each reaction. ${ }^{\mathrm{i}} \mathrm{PrOH}$ turned out to be the ideal solvent for this transformation, since the particles disperse much worse in more polar solvents like $\mathrm{MeOH}$ or $\mathrm{H}_{2} \mathrm{O}$. Tests also showed that the conversion in ${ }^{\mathrm{i}} \mathrm{PrOH}$ is much higher as in more unpolar solvents, e.g. in $\mathrm{CHCl}_{3}$. a)

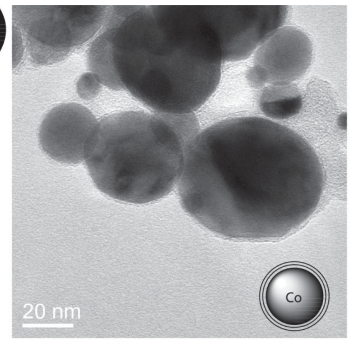

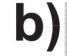

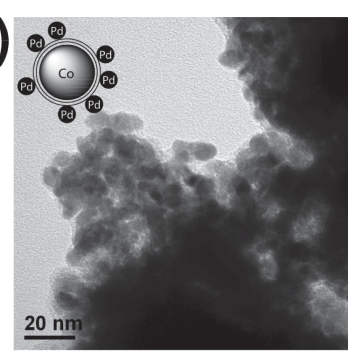

c)
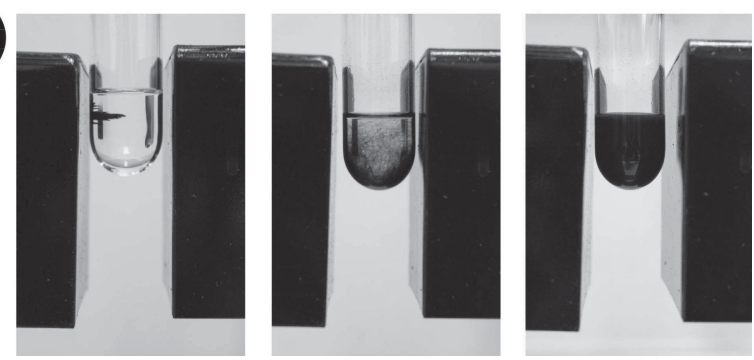

Figure 2. a) TEM pictures of pristine $\mathrm{Co} / \mathrm{C}$ nanobeads 1 . b) TEM pictures of Pd@Co/C 2c (4.4 wt\% Pd). c) Dispersing the nanoparticles without a stirring bar. The black boxes contain contrarily rotating permanent magnets. 
Table 2. Hydrogenation of trans-stilbene using Pd@Co/C. ${ }^{\text {a) }}$

\begin{tabular}{lccccc}
\hline entry & particles & $\begin{array}{c}\mathrm{Pd} \\
{[\mathrm{wt} \%]}\end{array}$ & $\begin{array}{c}t \\
{[\mathrm{~min}]}\end{array}$ & $\begin{array}{c}\text { conversion } \\
\left.[\%]^{\mathrm{b}}\right)\end{array}$ & $\begin{array}{c}\text { TOF } \\
\left.\left[\mathrm{h}^{-1}\right]^{\mathrm{c}}\right)\end{array}$ \\
\hline 1 & $\mathbf{2 b}$ & 8.8 & 60 & 30 & 300 \\
2 & $2 \mathrm{c}$ & 4.4 & 60 & 67 & 670 \\
3 & $\mathbf{2 d}$ & 1.6 & 60 & 98 & 980 \\
4 & $2 \mathrm{e}$ & 0.8 & 40 & 96 & 2015 \\
5 & $\mathbf{2 f}$ & 0.2 & 10 & 64 & 3845 \\
$6^{\mathrm{d})}$ & $\mathbf{2 f}$ & 0.2 & 10 & 18 & 1060 \\
$7^{\mathrm{e})}$ & $\mathbf{2 f}$ & 0.2 & 60 & 100 & 11095 \\
8 & $2 \mathrm{~g}$ & 0.4 & 40 & 78 & 1166 \\
9 & $2 \mathrm{~h}$ & 0.1 & 20 & 60 & 1793 \\
10 & $\mathbf{2 i}$ & 0.1 & 60 & 70 & 697 \\
11 & $2 \mathrm{j}$ & 0.1 & 60 & 68 & 681 \\
12 & - & - & 240 & 0.5 & n.d. \\
13 & $\mathbf{1}$ & - & 240 & 0.6 & n.d. \\
14 & $\mathrm{Pd} / \mathrm{C}$ & $1.8^{\text {f) }}$ & 60 & 59 & 585 \\
\hline
\end{tabular}

a) Stilbene $(0.5 \mathrm{mmol})$ in ${ }^{\mathrm{i}} \mathrm{PrOH}(5 \mathrm{~mL})$ was hydrogenated by $0.5 \mu \mathrm{mol} 2(0.1 \mathrm{~mol} \%$ Pd) adding dodecane as GC standard; 'b) Conversion determined by GC (gas chromatography) analysis using internal standard; ${ }^{c} \mathrm{Mol}$ of substrate transformed per mol of catalyst per hour; ${ }^{\text {d) }}$ No stirring bar; ${ }^{\text {e) }} 0.01$ mol\% catalyst loading, 10 bar $\mathrm{H}_{2}$ pressure; f) Equivalent to 0.2 wt $\%$ on the magnetic nanoparticles.

Comparing the turnover frequencies (TOFs), a clear trend of increasing activity with decreasing Pd content of the nanocomposites 2b-f is observed (Figure 1c). The data from the activity tests nicely fit the data for the exposed Pd surface obtained from CO pulse chemisorption. The very high TOF $\left(3845 \mathrm{~h}^{-1}\right)$ of the particles with $0.2 \mathrm{wt} \% \mathrm{Pd}$ (Table 2, entry 5) by far exceeds the TOFs for the same reaction catalyzed by palladium nanoparticles immobilized on magnetite beads (46-49 $\left.\mathrm{h}^{-1}\right)^{[16]}$ and Pd nanoparticles deposited on the surface of CNTs $\left(2820 \mathrm{~h}^{-1}\right){ }^{[13]}$ Due to the high saturation magnetization of the cobalt core dispersing and stirring of the nanocatalyst 2 was also possible by the application of an external rotating magnetic field (Figure 2c), dispensing from the need of an ultrasonic bath and an internal stirring bar. However, the conversion drops by two third compared to the reaction with stirring bar (Table 2, entry 6). This can be attributed to the possibility of more vigorous convection using an internal stirring bar, which is an important factor since the contact area with the hydrogen atmosphere is crucial in this reaction. Lowering the catalyst loading to $0.01 \mathrm{~mol} \%$, full conversion was obtained after only one hour by raising the hydrogen pressure to 10 bar. This low loading results in a extremely high TOF of $11095 \mathrm{~h}^{-1}$ (Table 2, entry 7), which to the best of our knowledge exceeds all reported TOFs of supported Pd catalysts for the hydrogenation of this particular substrate.

When nanocatalysts $2 \mathrm{~g}$ and $2 \mathrm{~h}$ were applied, which were synthesized by the decomposition of $\mathrm{Pd}_{2}(\mathrm{dba})_{3}$, considerably smaller TOFs were obtained compared to $\mathbf{2 f}$ (Figure 1c, Table 2), showing again the beneficial influence of the $\operatorname{Pd}_{2}(\mathrm{dba})_{3}$-chloroform adduct as the Pd source. However, the same trend of higher catalytic activity at lower Pd content is also observable in this case (Table 2, entry 8,9 ). The nanocomposites $2 \mathbf{b}$ and $2 c$ exhibit even lower catalytic activities regardless of the method of reduction (Table 2 , entry 10,11). These results might be reasoned by the reduced dispersability in water of 1 during the synthesis, which seems to be essential for the deposition of active Pd nanoparticles on the surface of these supports. Concluding from all the above results, $\operatorname{Pd}_{2}(\mathrm{dba})_{3} \cdot \mathrm{CHCl}_{3}$ is clearly the optimal $\mathrm{Pd}$ source regarding efficiency of $\mathrm{Pd}$ incorporation and catalytic activity.

Additionally, a series of control experiments was conducted. In the absence of nanocatalyst a negligible background conversion of $0.5 \%$ after $4 \mathrm{~h}$ of reaction time was observed (Table 2 , entry 12). Almost the same value was obtained using $\mathrm{Co} / \mathrm{C}$ nanoparticles 1 , excluding any relevant catalytic activity by the support itself (Table 2, entry 13). In another experiment, applying particles $\mathbf{2 f}$, the catalyst was collected by a magnet after $15 \mathrm{~min}$ of reaction time and the supernatant decanted into a fresh reaction tube. The conversion at this time was $72.3 \%$. Stirring the decanted solution for two more hours under hydrogen atmosphere led to an additional conversion of only $0.2 \%$, which correlates very well with the background activity.

Table 3. Hydrogenation of olefins and a nitro compound by Pd@Co/C catalyst $2 \mathrm{f}$. ${ }^{\text {) }}$

Entry

a) Substrate $(0.5 \mathrm{mmol})$ in ${ }^{\mathrm{P}} \mathrm{PrOH}(5 \mathrm{~mL})$ was hydrogenated by $0.5 \mu \mathrm{mol} 2 \mathrm{f}(0.2 \mathrm{wt} \%$ Pd) adding dodecane as GC standard; b) Determined by GC analysis using internal standard; c) Initial isomerization to $(E)$-oct-2-ene detectable. 
This experiment shows that indeed the supported Pd nanoparticles catalyze the reaction and not Pd that is dissolved in the reaction mixture. Finally, to probe the influence of the support on the catalytic activity, Pd was deposited on activated charcoal (Merck) using the exact same conditions as for the synthesis of the most active particles $2 \mathrm{f}$. The amount of palladium was adjusted to ensure the same Pd-C-ratio as in the nanocatalyst. The temperature ramping in the microwave, however, was considerably longer to reach the final temperature of $110{ }^{\circ} \mathrm{C}$ and the incorporation efficiency of $\mathrm{Pd}$ into the activated charcoal was only $86 \%$ in comparison to $100 \%$ in the case of 2 f. Moreover, the catalytic activity measured for this freshly prepared $\mathrm{Pd} / \mathrm{C}$ catalyst (Table 2 , entry 14 ) is only $15 \%$ of the activity of 2f under identical conditions. The better accessibility of active sites on the nano-globular particles $\mathbf{2 f}$ and/or an activating electronic effect of the cobalt core might account for this result.

In order to test the substrate scope and to classify the results obtained for trans-stilbene with respect to other substrates, various olefins and a nitro compound were evaluated under the same conditions applying nanocatalyst 2 f. Di- or tri-substituted olefins were successfully hydrogenated in reactions times similar to that of trans-stilbene (Table 3, entry 1-3). In $\alpha, \beta$-unsaturated compounds (Table 3 , entry 4,5) the alkene moiety was reduced selectively. Chalcone (Table 3, entry 4) was hydrogenated ten times slower than methyl cinnamate (Table 3, entry 5), which might be reasoned by the stronger electron withdrawing effect of the neighboring keto group compared to the ester group in methyl cinnamate. Styrene derivatives reacted in a very short reaction time of only ten minutes regardless if donor or acceptor substituents are present on the arene ring (Table 3, entry 6,7), as well as norbornene (Table 3, entry 8$)$. In the case of octane the starting material was consumed after 5 minutes according to GC measurements, however, a partial isomerization to $(E)$-oct-2-ene was detected and additional $40 \mathrm{~min}$ were needed to complete the hydrogenation to octane (Table 3, entry 9).

The cyclic analogue (Z)-cyclooctane turned out to be a more difficult substrate, needing $4 \mathrm{~h}$ for full conversion. Finally, 4-nitrotoluene was readily converted to the corresponding amine demonstrating that nitro compounds are also feasible substrates for nanocatalyst $2 \mathrm{f}$.

To further enhance the activity of the nanocatalyst by activation of the Pd surface, the use of additives was evaluated. Initial tests with different solvents revealed that the addition of ethers activate the nanocatalyst 2 . For more detailed studies of this effect, diethyl ether was chosen as additive since it is conveniently available and the low boiling enables easy removal from the product. Indeed, diethyl ether enhanced the TOF in the hydrogenation of trans-stilbene using catalyst $2 \mathrm{f}$ up to $30 \%$ (Figure 3a). The optimum ratio seems to be 10 vol\% of diethyl ether in ${ }^{\mathrm{P}} \mathrm{PrOH}$ leading to an extraordinary high TOF of $5507 \mathrm{~h}^{-1}$. Higher amounts of ether reduced the activity again, which could be explained with a lower ability of dissolving hydrogen. The activating effect of diethyl ether might be a general phenomenon for Pd nanoparticles, which will be further explored in other catalytic reactions.

Having determined the most active catalyst, the substrate scope, and the best conditions, the recovery and recycling of the catalyst remained of prevalent interest. A large-scale a)

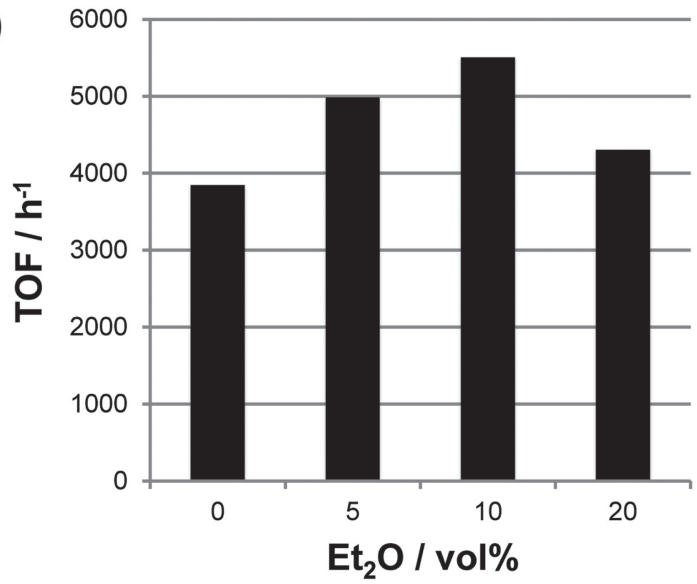

b)

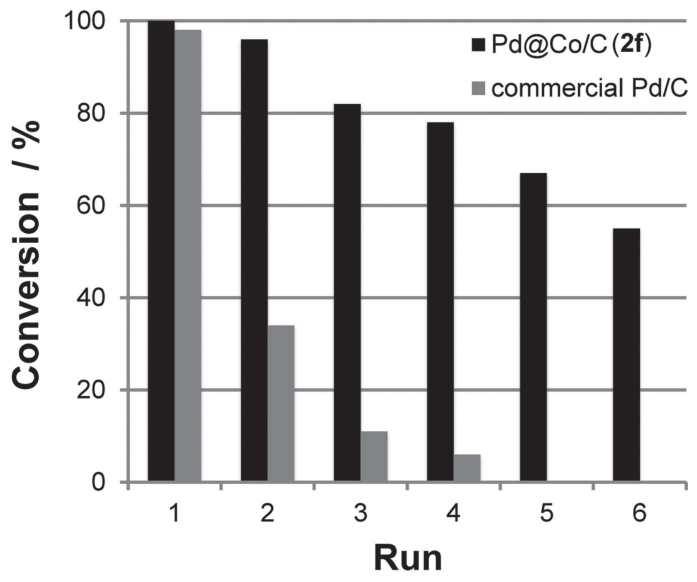

c)

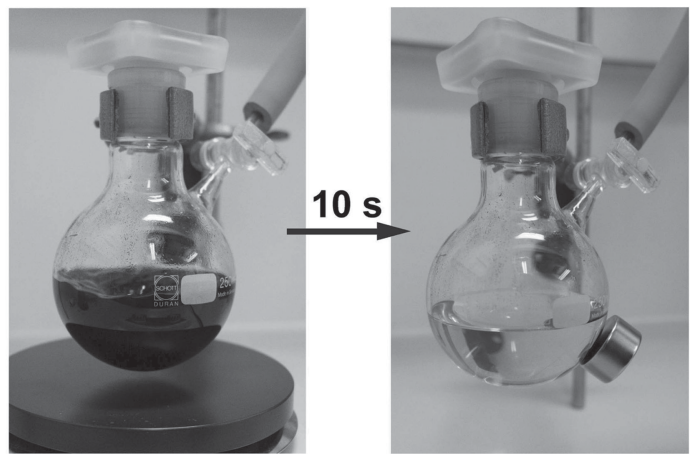

Figure 3. a) Effects of the addition of $\mathrm{Et}_{2} \mathrm{O}$ on the catalytic activity of catalyst $2 \mathrm{f}(0.1 \mathrm{~mol} \%)$ in the hydrogenation of trans-stilbene. b) Repetitive hydrogenation of trans-stilbene using $0.1 \mathrm{~mol} \%$ of Pd catalyst. The conversion of $\mathbf{2} \mathrm{f}$ was determined after $15 \mathrm{~min}$ for six consecutive runs and the conversion of commercial Pd/C (1 wt\%) after $270 \mathrm{~min}$ for four consecutive runs. c) The magnetic catalyst $2 \mathrm{f}$ can be recovered by an external magnet (silver colored cylinder) within seconds.

hydrogenation of trans-stilbene applying $0.1 \mathrm{~mol} \%$ catalyst $2 \mathrm{f}$ was set up, recycling the nanocatalyst after each run (Figure $3 \mathrm{~b}$ ). After a reaction time of $15 \mathrm{~min}$, a permanent magnet was moved to the side of the reaction flask, allowing the complete separation of the magnetic catalyst within seconds (Figure 3c), which is of great advantage compared to supports with inferior magnetization levels, e.g. iron oxide based nanoparticles. Thereafter, the 
Table 4. Consecutive large scale hydrogenation and determination of the leaching. a)

\begin{tabular}{ccccccc}
\hline & \multicolumn{2}{c}{ batch 1 } & & \multicolumn{3}{c}{ batch 2 } \\
\cline { 2 - 3 } \cline { 6 - 7 } run & $\begin{array}{c}\text { conversion after } \\
15 \text { min }[\%]^{c)}\end{array}$ & $\begin{array}{c}\text { TOF } \\
{\left[\mathrm{h}^{-1}\right]}\end{array}$ & & $\begin{array}{c}\text { time to full } \\
\text { conversion [min] }\end{array}$ & $\begin{array}{c}\text { leaching Pd } \\
{[\mathrm{ppm}]^{\mathrm{d})}}\end{array}$ & $\begin{array}{c}\text { leaching Co } \\
{[\mathrm{ppm}]^{\mathrm{d})}}\end{array}$ \\
\hline 1 & 100 & 3722 & & 15 & n.d. & n.d. \\
2 & 96 & 3668 & & 20 & $<2$ & 6 \\
3 & 82 & 3279 & & 35 & $<2$ & $<2$ \\
4 & 78 & 3116 & & 50 & 6 & 4 \\
5 & 67 & 2681 & & 90 & $<2$ & $<2$ \\
6 & 55 & 2203 & & 120 & $<2$ & 17 \\
\hline
\end{tabular}

a) Stilbene $(7.3 \mathrm{mmol})$ in ${ }^{\mathrm{P}} \mathrm{PrOH} / \mathrm{Et}_{2} \mathrm{O}(9: 1)$ was hydrogenated by $7.3 \mu \mathrm{mol} 2 \mathrm{f}$ ( 0.2 wt\% Pd) adding dodecane as GC standard; b) Each run was stopped at $100 \%$ conversion. No standard was added after run $1{ }^{\circ}{ }^{c}$ Conversion determined by GC analysis using internal standard; $\left.{ }^{d}\right) \ln \mu g$ per $g$ of product. Determined by ICP-OES.

product solution was simply decanted, being arguably more convenient than removal of conventional polymer, silica, or carbon supports by filtration or CNTs by centrifugation. After washing the magnetically recovered particles thoroughly, they were reused directly for the next run. In the first run, full conversion was reached after only $15 \mathrm{~min}$ with a TOF of $3722 \mathrm{~h}^{-1}$ (Table 4). While in the second run the conversion remained at a high level of $96 \%$ it constantly decreased in the following runs reaching $55 \%$ in the $6^{\text {th }}$ run at the same reaction time (Figure $3 \mathrm{~b}$ ), nevertheless, the TOF still exceeded 2000 cycles/hour.

In order to compare these results with a common hydrogenation catalyst, commercially available Pd on activated charcoal (Acros, 1 wt\% Pd) was also tested. The Pd loading was determined by ICP-EOS as $0.086 \mathrm{mmol} / \mathrm{g}$ and the values obtained by CO chemisorption $\left(d_{\mathrm{Pd}}=4.7 \mathrm{~nm}, S_{\mathrm{Pd}}=68 \mathrm{~m}^{2} \mathrm{~g}^{-1}, D_{\mathrm{Pd}}=\right.$ $29 \%$ ) are in the range of Pd@Co/C nanocatalysts with similar loadings (Table 1). Applying the commercial Pd/C in the hydrogenation of stilbene, however, the reaction time had to be raised to $4.5 \mathrm{~h}$ to reach nearly full conversion $(98 \%)$ in the first run at a catalyst loading of $0.1 \mathrm{~mol} \%$. The resulting TOF $\left(241 \mathrm{~h}^{-1}\right)$ is more than ten times lower as for the nanocatalyst $2 \mathrm{f}$ and even lower as $\mathrm{Pd} / \mathrm{C}$ synthesized by microwave deposition of $\mathrm{Pd}$ nanoparticles on activated charcoal (Table 2, entry 14). In order to recycle the $\mathrm{Pd} / \mathrm{C}$ catalyst, the solution was filtered from the insoluble catalyst and the catalyst was recovered from the filter. Inevitably, some catalyst material was lost during this tedious procedure, so, in contrast to the magnetic catalysts, the amount of substrate was adjusted for each run to compensate the loss of catalyst. The activity of the $\mathrm{Pd} / \mathrm{C}$ system, however, dropped by $65 \%$ after the first run and after four runs, only $6 \%$ conversion was determined resulting in a very low TOF of $14 \mathrm{~h}^{-1}$ (Figure 3b). Due to this greatly reduced activity, no further runs were carried out.

There are three possible explanations for the decrease of activity upon recycling of the Pd@Co/C nanocatalyst: (i) passivation of the surface, presumably via oxidation to Pd(II); (ii) leaching of the Pd from the support; (iii) agglomeration of the Pd nanoparticles on the carbon surface of the support. Oxidation of the surface, however, is unlikely since a reducing environment is prevalent throughout the course of reaction. Leaching of $\mathrm{Pd}$ from the supports or loss of the entire Pd@Co/C nanocatalyst was investigated also in view of the low limits for heavy metal impurities in products set by the pharmaceutical industry. ${ }^{[3]}$ While the decantation test discussed above already indicated a low leaching of active Pd species, the Pd and Co contamination in the final product was more precisely determined by ICPOES measurements. To quantify the metal content a second batch of trans-stilbene was hydrogenated, this time letting the reaction run to full conversion in each run (see the Supporting Information). The detected $\mathrm{Pd}$ content in the isolated product was always below the detection limit of our equipment ( $2 \mathrm{ppm}$ ) except of one run (Table 4). The contamination with cobalt was also in almost all runs at the threshold of the detection limit and only in one case a slightly higher Co contamination was measured probably due to the loss of a small amount of supports during magnetic separation. With one exception, however, the heavy metal concentrations are below $10 \mathrm{ppm}$, in agreement with the limit set by the industry. ${ }^{[3]}$ Moreover, the remaining Pd on the supports was determined for batch 1 ( 6 runs, each run $15 \mathrm{~min}$ ) as $100 \%$ of the initial loading and for batch 2 (6 runs, each run to full conversion) as $95 \%$.

The particularly negative results in the recycling of $\mathrm{Pd} / \mathrm{C}$ were underlined by the ICP-OES measurements where only $10 \%$ of the initial $\mathrm{Pd}$ was detected in the $\mathrm{Pd} / \mathrm{C}$ catalyst after four runs of catalysis, explaining the drop in activity. Even after filtering the solution twice, a contamination of $40 \mathrm{ppm}$ Pd was found in the hydrogenation product, which is way above the levels reached by the magnetic catalyst (Table 4).

Since these results exclude excessive leaching as the cause for the constant drop of activity from run to run for nanocatalyst $2 \mathrm{f}$, the possible agglomeration of the Pd nanoparticles on the graphene surface of the support was investigated. Comparing measurements of pulsed $\mathrm{CO}$ chemisorption of pristine catalyst $2 \mathrm{f}$ and the same catalyst after six runs reveal a slight increase in particle size from $2.7 \mathrm{~nm}$ to $3.1 \mathrm{~nm}$ and as a consequence thereof a drop in exposed surface from 121 to $113 \mathrm{~m}^{2} \mathrm{~g}^{-1}$ (Figure 1b). Also the dispersion of Pd declined from $47 \%$ to $42 \%$. Although all these values are conclusive with an aggregation of the nanoparticles, the differences seem to be too small to regard aggregation as the exclusive reason for the observed drop of activity. We therefore reason that a combination of deactivation modes such as aggregation of the $\mathrm{Pd}$ nanoparticles, small losses of entire nanocomposites, marginal leaching of Pd, and passivation of the surface by oxidation and/ or substrate or product inhibition could be responsible, nevertheless, it should be noted that the activity of the catalyst at run 6 with a TOF of $>2000 \mathrm{~h}^{-1}$ is still impressively high.

\section{Conclusion}

We describe the efficient and rapid microwave deposition of $\mathrm{Pd}$ nanoparticles on the surface of highly magnetic $\mathrm{Co} / \mathrm{C}$ nanobeads starting from $\mathrm{Pd}_{2}(\mathrm{dba})_{3} \cdot \mathrm{CHCl}_{3}$ and the extensive characterization of the resulting hybrid material. This method proved to be superior to established routes which proceed via reduction of $\mathrm{Pd}(\mathrm{II})$ sources. We demonstrate that the catalytic activity of the nanocomposites rises considerably with decreasing the Pd loading. Extraordinary high turnover frequencies $\left(3845 \mathrm{~h}^{-1}\right)$ 
were achieved for the hydrogenation of trans-stilbene exceeding not only all literature reports for supported Pd nanoparticles, but also comparable Pd/C catalysts by far. Furthermore, the catalytic activity was significantly enhanced adding 10 vol\% $\mathrm{Et}_{2} \mathrm{O}$. The particles were rapidly separated by applying an external magnet and reused for six consecutive runs. A noticeable loss of activity was observed after the second run with only marginal leaching of Pd and Co detectable. However, slight agglomeration of the Pd nanoparticles on the supports was determined by pulsed CO chemisorption measurements.

These novel magnetic nanocatalysts are superior to the industry standard $\mathrm{Pd} / \mathrm{C}$ in every relevant aspect. They feature a way higher initial activity, a much more convenient separation, better recycling, and less contamination of the products. Last but not least, they can be very easily prepared from commercially available $\mathrm{Co} / \mathrm{C}$ nanoparticles and $\mathrm{Pd}_{2}(\mathrm{dba})_{3} \cdot \mathrm{CHCl}_{3}$ using standard laboratory equipment.

\section{Experimental Section}

Representative Procedure for the Microwave Synthesis of Pd@Co/C Catalyst 2f: $\mathrm{Co} / \mathrm{C}$ nanoparticles 1 (1.0 g, $7.8 \mathrm{wt} \% \mathrm{C}), \mathrm{Pd}_{2}(\mathrm{dba})_{3} \cdot \mathrm{CHCl}_{3}$ (7.8 $\mathrm{mg}, 15 \mathrm{mmol}$ ) and dry toluene $(5 \mathrm{~mL})$ were introduced to a microwave vial under nitrogen atmosphere. The reaction mixture was sonicated in an ultrasonic bath for $10 \mathrm{~min}$ and then heated in a focused microwave oven to $110^{\circ} \mathrm{C}$ for $2 \mathrm{~min}$. The magnetic catalyst was recovered by an external magnet, the solution decanted, and the particles washed with $\mathrm{CH}_{2} \mathrm{CL}_{2}(5 \times 5 \mathrm{~mL})$. After drying under vacuum a loading of $14.6 \mu \mathrm{mol} / \mathrm{g}(97 \%)$ was determined by ICP-OES.

General Procedure for the Hydrogenation Using Pd@Co/C: To a schlenk tube Pd@Co/C nanoparticles 2 (0.1 mol\% Pd, $0.5 \mu \mathrm{mol})$, substrate $(0.5 \mathrm{mmol})$ and $\mathrm{PrOH}(5 \mathrm{~mL})$ were introduced. Dodecane $(0.5 \mathrm{mmol})$ was added as internal standard and the slurry sonicated in an ultrasonic bath for $10 \mathrm{~min}$. The tube was evaporated and flushed with $\mathrm{H}_{2}$ several times followed by vigorous stirring under $1 \mathrm{~atm} \mathrm{H}_{2}$ (balloon). The progress of the reaction was monitored by gas chromatography (GC) separating the magnetic material by an external magnet before sampling.

\section{Supporting Information}

Supporting Information is available from the Wiley Online Library or from the author.

\section{Acknowledgements}

This work was financially supported by the International Doctorate Program (Elitenetzwerk Bayern), the Deutsche Forschungsgemeinschaft (DFG) (Re 948/8-1, "GLOBUCAT"), and the EU-ITN network Mag(net) icFun (PITN-GA-2012-290248). We thank Turbobeads Llc for generously providing the magnetic nanobeads. We gratefully acknowledge the help of Joachim Rewitzer, Florian Pielnhofer, Richard Weihrich, and Martin Zeltner.

Received: September 23, 2013 Published online: November 20, 2013

[1] W. Bonrath, J. Medlock, J. Schutz, B. Wustenberg, T. Netscher in Hydrogenation (Ed: I. Karam), InTech, Rijeka, Croatia 2012.

[2] a) R. A. Sheldon, Chem. Commun. 2008, 3352; b) P. T. Anastas, M. M. Kirchhoff, Acc. Chem. Res. 2002, 35, 686-694; c) P. T. Anastas, J. C. Warner, Green Chemistry, Theory and Practice, Oxford University Press, Oxford 1998.
[3] a) V. L. Budarin, P. S. Shuttleworth, J. H. Clark, R. Luque, Curr. Org. Synth. 2010, 7, 614-627; b) C. E. Garrett, K. Prasad, Adv. Synth. Catal. 2004, 346, 889-900.

[4] a) K. V. S. Ranganath, F. Glorius, Catal. Sci. Technol. 2011, 1, 13-22; b) R. A. Sheldon, J. Environ. Monit. 2008, 10, 406; c) R. A. Sheldon, $\mathrm{H}$. van Bekkum, Fine Chemicals through Heterogeneous Catalysis, Wiley-VCH, Weinheim 2001.

[5] V. Polshettiwar, R. Luque, A. Fihri, H. Zhu, M. Bouhrara, J.-M. Basset, Chem. Rev. 2011, 111, 3036-3075.

[6] a) S. Shylesh, V. Schünemann, W. R. Thiel, Angew. Chem., Int. Ed. 2010, 49, 3428-3459; b) L. N. Lewis, Chem. Rev. 1993, 93, 26932730; c) A. Roucoux, J. Schulz, H. Patin, Chem. Rev. 2002, 102, 3757-3778.

[7] a) B. J. Gallon, R. W. Kojima, R. B. Kaner, P. L. Diaconescu, Angew. Chem. Int. Ed. 2007, 46, 7251-7254; b) K. Mennecke, A. Kirschning, Beilstein J. Org. Chem. 2009, 5; c) Y. Mei, Y. Lu, F. Polzer, M. Ballauff, M. Drechsler, Chem. Mater. 2007, 19, 1062-1069; d) Y. Li, X. M. Hong, D. M. Collard, M. A. El-Sayed, Org. Lett. 2000, 2, 23852388; e) R. Narayanan, M. A. El-Sayed, J. Am. Chem. Soc. 2003, 125, $8340-8347$.

[8] a) N. Erathodiyil, S. Ooi, A. M. Seayad, Y. Han, S. S. Lee, J. Y. Ying, Chem. Eur. J. 2008, 14, 3118-3125; b) S. Jana, B. Dutta, R. Bera, S. Koner, Inorg. Chem. 2008, 47, 5512-5520; c) R. B. Bedford, U. G. Singh, R. I. Walton, R. T. Williams, S. A. Davis, Chem. Mater. 2005, 17, 701-707; d) C.-H. Tu, A.-Q. Wang, M.-Y. Zheng, X.-D. Wang, T. Zhang, Appl. Catal. A-Gen. 2006, 297, 40-47.

[9] a) S. Mandal, D. Roy, R. V. Chaudhari, M. Sastry, Chem. Mater. 2004, 16, 3714-3724; b) M. Dams, J. Catal. 2002, 209, 225-236; c) L. Djakovitch, K. Koehler, J. Am. Chem. Soc. 2001, 123, 5990-5999.

[10] a) J. Huang, D. Wang, H. Hou, T. You, Adv. Funct. Mater. 2008, 18, 441-448; b) N. N. Kariuki, X. Wang, J. R. Mawdsley, M. S. Ferrandon, S. G. Niyogi, J. T. Vaughey, D. J. Myers, Chem. Mater. 2010, 22, 4144-4152; c) K. Köhler, R. G. Heidenreich, J. G. E. Krauter, J. Pietsch, Chem. Eur. J. 2002, 8, 622-631; d) G. Marck, A. Villiger, R. Buchecker, Tetrahedron Lett. 1994, 35, 3277-3280; e) S. H. Joo, S. J. Choi, I. Oh, J. Kwak, Z. Liu, O. Terasaki, R. Ryoo, Nature 2001, 412, 169-172.

[11] a) N. Li, Z. Wang, K. Zhao, Z. Shi, S. Xu, Z. Gu, J. Nanosci. Nanotech. 2010, 10, 6748-6751; b) A. R. Siamaki, A. E. R. S. Khder, V. Abdelsayed, M. S. El-Shall, B. F. Gupton, J. Catal. 2011, 279, 1-11; c) G. M. Scheuermann, L. Rumi, P. Steurer, W. Bannwarth, R. Mülhaupt, J. Am. Chem. Soc. 2009, 131, 8262-8270; d) Y. Li, X. Fan, J. Qi, J. Ji, S. Wang, G. Zhang, F. Zhang, Nano Res. 2010, 3, 429-437.

[12] a) M. Rueping, R. M. Koenigs, R. Borrmann, J. Zoller, T. E. Weirich, J. Mayer, Chem. Mater. 2011, 23, 2008-2010; b) X. Pan, Z. Fan, W. Chen, Y. Ding, H. Luo, X. Bao, Nat. Mater. 2007, 6, 507-511.

[13] Y. S. Chun, J. Y. Shin, C. E. Song, S.-g. Lee, Chem. Commun. 2008, 942.

[14] M. Cano, A. Benito, W. K. Maser, E. P. Urriolabeitia, Carbon 2011, 49, 652-658.

[15] a) Q. Du, W. Zhang, H. Ma, J. Zheng, B. Zhou, Y. Li, Tetrahedron 2012, 68, 3577-3584; b) M. Zhu, G. Diao, J. Phys. Chem. C 2011, 115, 24743-24749; c) V. S. Coker, J. A. Bennett, N. D. Telling, T. Henkel, J. M. Charnock, G. van der Laan, R. A. D. Pattrick, C. I. Pearce, R. S. Cutting, I. J. Shannon, J. Wood, E. Arenholz, I. C. Lyon, J. R. Lloyd, ACS Nano 2010, 4, 2577-2584.

[16] a) J.-Y. Shin, Y.-R. Jung, S.-J. Kim, S.-g. Lee, Bull. Korean Chem. Soc. 2011, 32, 3105-3108; b) A. J. Amali, R. K. Rana, Green Chem. 2009, $11,1781$.

[17] S. Chandra, S. Bag, P. Das, D. Bhattacharya, P. Pramanik, Chem. Phys. Lett. 2012, 519-520, 59-63.

[18] J. Hu, Y. Wang, M. Han, Y. Zhou, X. Jiang, P. Sun, Catal. Sci. Technol. 2012, 2, 2332. 
[19] S. C. Tsang, V. Caps, I. Paraskevas, D. Chadwick, D. Thompsett, Angew. Chem. Int. Ed. 2004, 43, 5645-5649.

[20] A.-H. Lu, W. Schmidt, N. Matoussevitch, H. Bönnemann, B. Spliethoff, B. Tesche, E. Bill, W. Kiefer, F. Schüth, Angew. Chem. Int. Ed. 2004, 43, 4303-4306.

[21] R. N. Grass, E. K. Athanassiou, W. J. Stark, Angew. Chem. Int. Ed. 2007, 46, 4909-4912.

[22] A. K. Tucker-Schwartz, R. L. Garrell, Chem. Eur. J. 2010, 16, 12718-12726.

[23] N. Osterwalder, C. Capello, K. Hungerbühler, W. J. Stark, J. Nanopart. Res. 2006, 8, 1-9.

[24] Q. M. Kainz, A. Schätz, A. Zöpfl, W. J. Stark, O. Reiser, Chem. Mater. 2011, 23, 3606-3613.

[25] A. Schätz, R. N. Grass, W. J. Stark, O. Reiser, Chem. Eur. J. 2008, 14, $8262-8266$

[26] a) M. Keller, V. Collière, O. Reiser, A.-M. Caminade, J.-P. Majoral, A. Ouali, Angew. Chem. 2013, 125, 3714-3717; b) M. Keller, A. Perrier, R. Linhardt, L. Travers, S. Wittmann, A.-M. Caminade, J.-P. Majoral, O. Reiser, A. Ouali, Adv. Synth. Catal. 2013, 355, 1748-1754; c) A. Schätz, O. Reiser, W. J. Stark, Chem. Eur. J. 2010, 16, 8950-8967; d) S. Wittmann, A. Schätz, R. N. Grass, W. J. Stark, O. Reiser, Angew. Chem. Int. Ed. 2010, 49, 1867-1870.

[27] a) R. Fuhrer, I. K. Herrmann, E. K. Athanassiou, R. N. Grass, W. J. Stark, Langmuir 2011, 27, 1924-1929; b) M. Rossier, M. Schreier, U. Krebs, B. Aeschlimann, R. Fuhrer, M. Zeltner R. N. Grass, D. Günther, W. J. Stark, Sep. Purif. Technol. 2012, 96, 68-74; c) Q. M. Kainz, A. Späth, S. Weiss, T. D. Michl, A. Schätz, W. J. Stark, B. König, O. Reiser, ChemistryOpen 2012, 1, 125-129 d) M. Rossier, A. Schaetz, E. K. Athanassiou, R. N. Grass, W. J. Stark, Chem. Eng. J. 2011, 175, 244-250; e) F. M. Koehler M. Rossier, M. Waelle, E. K. Athanassiou, L. K. Limbach,
R. N. Grass, D. Günther, W. J. Stark, Chem. Commun. 2009, 48624864; f) M. Rossier, F. M. Koehler, E. K. Athanassiou, R. N. Grass, B. Aeschlimann, D. Günther, W. J. Stark, J. Mater. Chem. 2009, 19, 8239-8243; g) M. Rossier, F. M. Koehler, E. K. Athanassiou, R. N. Grass, M. Waelle, K. Birbaum, D. Günther, W. J. Stark, Ind. Eng. Chem. Res. 2010, 49, 9355-9362.

[28] a) I. K. Herrmann, R. E. Bernabei, M. Urner, R. N. Grass, B. Beck-Schimmer, W. J. Stark, Nephr. Dial. Transpl. 2011, 26, 2948-2954; b) I. K. Herrmann, M. Urner, F. M. Koehler, M. Hasler, B. Roth-Z'Graggen, R. N. Grass, U. Ziegler, B. Beck-Schimmer, W. J. Stark, Small 2010, 6, 1388-1392.

[29] A. Schätz, R. N. Grass, Q. Kainz, W. J. Stark, O. Reiser, Chem. Mater. 2010, 22, 305-310.

[30] a) A. Schätz, M. Zeltner, T. D. Michl, M. Rossier, R. Fuhrer, W. J. Stark, Chem. Eur. J. 2011, 17, 10566-10573; b) Q. M. Kainz, R. Linhardt, P. K. Maity, P. R. Hanson, O. Reiser, ChemSusChem 2013, 6, 721-729; c) Q. M. Kainz, M. Zeltner, M. Rossier, W. J. Stark, O. Reiser, Chem. Eur.J. 2013, 19, 10038-10045; d) A. Schätz, T. R. Long, R. N. Grass, W. J. Stark, P. R. Hanson, O. Reiser, Adv. Funct. Mater. 2010, 20, 4323-4328; e) P. K. Maity, A. Rolfe, T. B. Samarakoon, S. Faisal, R. D. Kurtz, T. R. Long, A. Schätz, D. L. Flynn, R. N. Grass, W. J. Stark, O. Reiser, P. R. Hanson, Org. Lett. 2011, 13, 8-10; f) P. K. Maity, Q. M. Kainz, S. Faisal, A. Rolfe, T. B. Samarakoon, F. Z. Basha, O. Reiser, P. R. Hanson, Chem. Commun. 2011, 47, 12524-12526.

[31] a) A. Balanta, C. Godard, C. Claver, Chem. Soc. Rev. 2011, 40, 4973 b) D. Kim, S. Hu, P. Tarakeshwar, K. S. Kim, J. M. Lisy, J. Phys. Chem. A 2003, 107, 1228-1238.

[32] S. Wittmann, J.-P. Majoral, R. N. Grass, W. J. Stark, O. Reiser, Green Proc. Synth. 2012, 1, 275-279. 